\title{
Factors Inhibiting Hispanic Parents’' School Involvement
}

\author{
Jay Smith \\ The Irving Independent School District, Irving, Texas \\ Kenneth Stern \\ Oklahoma State University \\ Zhanna Shatrova \\ Oklahoma State University
}

\begin{abstract}
Factors inhibiting Hispanic parental involvement in non-metropolitan area schools were studied. With the mandates of No Child Left Behind intensifying the need to improve the academic achievement of all at-risk groups of students in American schools, and with the relatively new phenomenon of large numbers of Hispanics settling in non-metropolitan areas, findings of this qualitative study of fifteen Hispanic parents should be highly useful to educators working with Hispanic youth. Primary factors inhibiting Hispanic parental involvement were the following: the failure of the school to send correspondence, school calendar, lunch menus or newsletters written in Spanish; the inability of the parents to speak and understand English in personal communication with the school, and the reluctance of the parents to question authority or to advocate for the rights of their children.
\end{abstract}

\section{Introduction}

The rapid influx of Hispanic students in America's schools is placing pressure on these schools as they attempt to meet the mandates of No Child Left Behind. Hispanics have become the largest ethnic group in the United States (U.S. Census Bureau, 2000). The stereotypical view of Hispanics, held by many in the not-so-distant past, was of migrant workers moving with the harvest or other seasonal work. According to the U.S. Department of Agriculture (2002), many Hispanics who initially entered this country as migrant or seasonal workers have selected communities in which to put down roots as they seek a more permanent way of making a living than following the agricultural harvests. Thus, rural and non-metropolitan areas have become the destinations where increasing numbers of Hispanic immigrants decide to settle down.

Between English-as-second-language and newly-arrived families present challenges for rural schools. Oftentimes, rural schools and communities lack the resources found in metropolitan areas (e.g., bilingual teachers, books and materials in Spanish, and Catholic churches) resulting in less communication with the Hispanic families. Educators believe parental involvement, regardless of ethnicity, is crucial for students' academic achievement. If educators are to be successful in establishing and maintaining communications, thus encouraging parental involvement, they must know and understand any obstacles inhibiting this involvement. This study gave fifteen Hispanic parents an opportunity to identify and describe their inability to be engaged with professional school personnel.
The number of Hispanic students has tripled in the past 30 years and predictions are that over one-fourth of K-12 students in 2030 will be Hispanic (Gibson, 2002). In a relatively short span of time, Hispanics, defined by the National Center for Education Statistics (N.C.E.S., 2002) as persons of "Cuban, Mexican, Puerto Rican, Southern or Central American or other Spanish culture or origin regardless of race" (p.1) have become the largest ethnic group in the U.S. (U.S. Census Bureau, 2000). By the time of the 2000 Census, Hispanics in increasing numbers were migrants to non-metropolitan and rural areas. This trend was the opposite of that identified in the 1990 Census where Hispanics were migrants to metropolitan areas. Sizable numbers of these settlers in non-metropolitan areas lack high school degrees, proficiency in English language skills, and naturalized immigration status (U.S. Department of Agriculture, U.S.D.A., 2002).

Though united by a common language, Hispanics in the U.S. are very diverse in socio-economic status, race, age, country of origin, the nature and timing of their immigration, and the degree of their acculturation (Nicolau \& Ramos, 1990). Haycock and Duany (1991) stated that differences among Hispanic subgroups in communication styles and socialization practices might be greater than the overall differences between Hispanics and non-Hispanics. Such diversity within the Hispanic population can add to the difficulties in developing strategies to increase meaningful parental involvement with their children's schools. However, specific to this current study, all of the Hispanics interviewed were of Mexican origin. 


\section{Barriers to Academic Success}

Prospects for the academic success of Hispanic students, regardless of location in the U.S. are not good if current statistical trends continue. Hispanic youth, in general, are "the most under-educated major segment of the U.S. population” (Inger, 1992, p.2) and have the highest drop-out rate of any ethnic group (Gibson, 2002). Several reports document the tendency for Hispanic students to dropout of school at a rate higher than the general population (Brown, Rosen, Hill, \& Olivas, 1980; Gibson, 2002; National Council of La Raza, 1992; Valverde, 1987).

Some of the causes of this under-education and subsequent dropout may be attributed to language barriers, low expectations of teachers, poverty, racism, and isolation with poor communication and cooperation among the school, parents, and community (Scribner, Young \& Pedroza, 1999). Low levels of parental involvement have been linked with low academic achievement while higher levels of parental involvement influence higher achievement (Henderson \& Mapp, 2002). Though research shows a connection between parental involvement and student achievement and, while several studies have shown that Hispanic parents care very much about their children's education (Trumbull, Rothstein-Fisch, Greenfield \& Quiroz, 2001), this minority parent participation in the schooling process of their offspring is decreasing (Floyd, 1998).

Hispanic parents often demonstrate low levels of involvement in their children's schools (Ferrer, 2007; Costa, 1991; Bauch, 1992). These parents care about their children's education, yet they do not become involved in their schools. A partial explanation of this paradox may be with the obstacles encountered by Hispanic parents: the language barrier, a lack of trust, a lack of understanding of the operation of school, logistical issues, and a lack of education of the parents themselves (Bauch, 1992).

Culture may dictate what it means for parents to be involved. Scribner, Young, and Pedroza (1999), in a Texas study, found that teachers tended to define parental involvement as participation in formal activities such as meetings and school events while Hispanic parents defined involvement as working in informal home activities: checking homework, reaching to children, and listening to children read. However, the differences do not end here. Instead, differences arise in the expected roles of teachers and parents. Hispanic parents highly respect teachers (Chavkin \& Gonzalez, 1995) and believe that it is the school's responsibility to instill knowledge. On the other hand, they view their role as providing nurturance and teaching morale, respect, and behavior (Carger, 1997). If Hispanic parents are asked to assume more responsibilities that they view as the schools, they may be reluctant, in part, because they believe they are overstepping their own boundaries (Sosa, 1997). Teachers may view parental questions about assignments and grades indicating the level of parental care, but Latino parents may view this as showing disrespect (Trumbull, Rothstein-Fisch, Greenfield \& Quiroz, 2001).

Not only do Hispanic parents care greatly about their children's education, they want to be involved (Lopez, 2001). Espinosa (1995), Lopez (2001), and Scribner, Young, and Pedroza (1999) indicate that Hispanic parents and families are very involved in their children's lives, but not necessarily in traditional ways. They also have high goals for their children tied to academic achievement (Shannon, 1996). If Hispanic students are going to succeed in the public schools, and if public school educators expect Hispanic parents to increase their involvement as defined by the public school, obstacles deterring this involvement must be identified and solutions must be found to overcome them.

How Hispanic parents adapt to American society will be related to how they interact with the schools. Schmid (2001) identified three primary types of adaptation to American society: acculturation to the middle class (parallel acculturation of all ethnic and racial groups into the white, middle class); assimilation into underclass (places the immigrant into a permanent underclass); and economic advancement with a distinct cultural identity (immigrants preserve their community's values and solidarity, but find ways to achieve economic success). The adaptation of an immigrant group depends on several complex and interacting factors. Family SES is a dominant factor. While some immigrant groups, such as Asians, tend to do well in academic and economic arenas, other groups, such as Hispanics, generally do not. SES and family background are most influential in the relatively low academic achievement of second-generation Mexican-American students. "The stark reality is that the economic conditions of Latino children are much more likely than those of other children to be dire" (Schmid, 2001). Perhaps, the most important obstacle to Hispanic parents becoming involved with the schools is the language barrier (Chavkin \& Gonzalez, 1995; Hyslop, 2000). In the majority of schools, teachers speak little or no Spanish (Chavkin \& Gonzalez, 1995; Gibson, 2002), making communication about grades, behavior, or homework difficult. Oftentimes, schools do not provide interpreters at parent meetings resulting in little understanding for Spanish speaking parents (Scribner, Young, \& Pedroza, 1999). When attempts by schools to translate documents into Spanish are made, frequently, these attempts are based on the assumptions about the level of acculturation of parents, thus resulting in the loss of intended meanings. Also, when homework is assigned in English, many parents are unable to help their children (Aspiazu, Bauer \& Spillett, 1998).

A “disconnect” may exist between the school culture and the Hispanic home culture with neither side valuing or understanding the other (Gibson, 2002). Hispanic families value social responsibilities, the well being of the group, and interdependent relationships above individual fulfillment and choice (Trumbull, Rothstein-Fisch, Greenfield, \& Quiroz, 2001). Since American schools often stress 
competition within schools and individual achievement over cooperative behaviors, Hispanic children often get mixed messages.

Other factors presenting barriers for involvement with the school and effective communication are: the parent's level of education (Floyd, 1998), previous negative experiences with school (Chavkin \& Gonzalez, 1995; Lopez, 2001; Scribner, Young, \& Pedroza ,1999), Hispanic parents feeling intimidated by teachers (Hyslop, 2000) and limited exposure of migrant families to schooling (Lopez, 2001). Lack of time for many Hispanics who work long hours (Sosa, 1997; Fuentes, Cantu, \& Stechuk, 1996), children and transportation (Floyd, 1998; Hampton, Mumford, \& Bond, 1998), and scheduling of events (Scribner, Young, \& Pedroza, 1999) are logistical issues mitigating against school involvement.

\section{Method and Purpose}

A qualitative study was devised with the lines of questioning shaped by the issues previously identified in this study from the research literature pertaining to the involvement of Hispanic parents in metropolitan schools such as the language barrier, cultural differences, a lack of trust, a lack of understanding of the operation of school, logistical issues, and a lack of education of the parents themselves. Fifteen Hispanic parents with little or no English language comprehension were selected from the larger Hispanic community in the rural (here defined as a community that is not part of a Metropolitan Statistical area) Midwestern district where their children attended school. The purpose of the study was to identify the major impediments to greater involvement of Hispanic parents with their children's schools through interviews and focus groups.

A local English language learner (ELL) teacher was contacted and asked to notify members of the Hispanic community of the purpose of the research and to invite them to participate as volunteers. Participants selected for individual and focus group interviews self identified as being non-English speakers. Subjects in this study were selected in a typical case sampling procedure according to what is typical, average, or normal. This approach was chosen to describe a culture or phenomenon to people not familiar with the setting studied (Patton, 2002). A key informant-a Hispanic woman fluent in Spanish and serving as the ELL teacher in the school district where the subjects lived who could identify who and what are typical, selected seven subjects for the study. This person is well respected in the adult Hispanic community and serves as a resource person for Hispanic parents in their efforts to communicate with the schools and other community agencies.

The interpreter for the interview process was a bilingual female parent who acted as a liaison and advocate for other parents because of her English fluency and her interest in helping Hispanic children to succeed in school. The interpreter's value to the process was enhanced because of her rapport with the subjects studied.

Subjects were interviewed individually and through a focus group. All of these interviews were tape-recorded; translation was then accomplished by a skilled bilingual adult who could detect the subtleties and nuances of the language. Individual interviews occurred in the subjects' homes. Findings from theses interviews informed the development of structured questions for use with the followup focus group interviews which occurred at a local Mexican restaurant.

Five primary research questions were designed to elicit information through the individual and focus group interviews:

1) Why are Hispanic parents settling in one nonmetropolitan area, generally, not involved with their children's schools?

2) What factors do the parents identify as the most significant obstacles presenting involvement with their children's schools?

3) Why are these factors similar or different from those identified in previous research of the large number of Hispanics who settled in metropolitan areas?

4) What, if any, are the yet undiscovered factors influencing the lack of involvement of Hispanic parents?

5) What insight can be gained form the parents' description of the barriers to greater involvement that might be used to address the problem identified?

\section{Findings}

The research previously identified in this study discussed the following factors that impede Hispanic parent involvement: the school's low level of receptivity and cordiality as perceived by the parents (Bauch, 1992; Lopez, 2001); the lack of effective communication channels between parents and the school (Chavkin \& Gonzalez, 1995; Scribner, Young \& Pedroza, 1999); the low level of support training and encouragement given by the school to enlist greater parent participation (Gibson, 2002); low English proficiency of the parents (Chavkin \& Gonzalez, 1995; Hyslop, 2000); lack of child care; economic and transportation issues (Floyd, 1998; Hampton, Mumford, \& Bond, 1998); and parental aspiration for their children's success (Costa, 1991; Bauch, 1992).

The current study confirmed some of the previously identified inhibiting factors and also found different ones. Parents described how the failure of the school to send general information letters, school calendars, lunch menus, or newsletters printed in Spanish resulted in confusion for the children and the parents. For example, the children would arrive at school on "free dress day" wearing the required daily school uniform or would be dressed and 
waiting for the bus on the professional development day for the teachers.

The inability of the parents to speak and understand English was the major obstacle to effective communications between the school and the Hispanic parents. All of the respondents described their ability to speak English as nonexistent or very low, though six out of seven indicated that their ability to understand some English exceeded their ability to speak it. The parents perceived their children's ability to understand and speak English as being moderate to high. Consequently, it was common practice for parents to use their children as interpreters for communication between the parents and the school. While English was the language spoken at school, Spanish was the language of the home.

Parents expressed a reluctance to question authority or advocate for the rights of their children. Parental expectation of what a child should be taught in school varied greatly with the only subject of agreement being English. Other priorities ranged from specific subjects (e.g. math, art, and social studies) to behavioral objectives (e.g. obedience, learning to show respect, and learning to listen quietly). Participants were unanimous in the opinion that their role in helping the children to succeed was to supervise the completion of homework. Another high priority for parents was motivating their children to work hard and to behave appropriately. However, the parents were reluctant to talk to the teacher or the administrator if there was a problem at school. One parent, in particular, said it would be awkward to do this since he used his child as an interpreter when he communicated with the school. Another parent mentioned a friend of hers who had quietly removed her child from the school because of discriminatory actions by the teacher toward her child. This mother did not want to confront the principal. The parents interviewed felt that they had a major responsibility to prepare children to learn by teaching them to work hard and be respectful, and that the teachers were seen as authorities of great knowledge and power and should be accorded appropriate respect. Essentially, these parents saw their own role was to see that homework is completed, that children are prepared for and go to school regularly, and that they behave appropriately at school. The teachers' role as seen by the parents is to teach so that the children learn.

The obstacles to parental involvement that emerged in other research but not in the present study were: lack of child care, transportation issues, fear of unacceptable attitude and behavior from contact with American popular culture, lack of receptive and cordial environment at the school, and low level parental aspirations for their children's success. Purposeful sampling serves the objectives of the research but might result in selective information. The interpreter commented to the researcher that the parents' willingness to participate in the interviews indicated that they were interested in the education of their children. She said, "Some parents don't care about their kids, and they wouldn't be interested at all in talking with you about any of this." It is possible that a random selection of participants might have produced more obstacles.

Schmid (2001) identified key factors significant in explaining differences in achievement among immigrant groups as their ability to assimilate into middle class white culture and the response of the existing culture of the immigrant groups. Significant in the current research is the adults' stated desire to learn to speak English to fit into the existing culture and the experienced cordiality from the school staff. The desire of the Hispanics to assimilate into the majority culture and the cordial response they report upon interaction with school staff seem to indicate a healthy movement toward cultural integration.

Following the individual family interviews, the researcher met with six Hispanic parents, four mothers and one husband and wife couple, as a focus group. Individuals invited to participate were identified through the same process as for the individual interviews. They expressed willingness to participate, and the ELL teacher invited them. All of the participants knew each other. Written communications from the school, either in English or in a difficult-to-understand Spanish translation, was identified as a major obstacle. However, those participants who could speak a little English sometimes felt uncomfortable answering certain questions. One of the mothers somewhat fluent in English stated that communication was frequently difficult in spite of her ability to speak English. For example, the researcher's question regarding how they could respond to some kind of injustice to their children at school was met with silence. Whether due, primarily, to cultural conditioning or fear of reprisal to themselves or others because of the unknown immigration status, they definitely felt discomfort with the question.

The focus group members were friendly and courteous. In some ways they were more relaxed than the parents in the individual interviews. On the other hand, they seemed more reluctant to respond to difficult questions. No new information was obtained in this setting; rather the responses confirmed and clarified that obtained in the one-to-one interviews.

\section{Recommendations for Action and Further Research}

If increased communication is to occur, schools will need to translate written materials into Spanish. Commonly used computer translation programs produce unintelligible materials that need to be checked by someone fluent in Spanish. Because parents expressed a willingness to learn English, schools should offer English language instruction after hours. Schools are a natural venue for this. While schools are making progress in helping Hispanic students feel welcome, additional efforts are needed to encourage greater involvement. Care must be taken to treat the Hispanic students equitably. The reluctance to question school authority and actions make the Hispanic parents and students vulnerable to abuses and treatment. Additionally, 
illegal immigration status results in many of these parents remaining silent and distant from school.

Further research could be focused on several areas. A study of successful schools on effective communication practices and document preparation in Spanish would be very beneficial for a lot of schools, especially in rural areas. Attendant to these communications, do these schools achieve greater parental involvement in schools activities? After hours English language instruction for Hispanic parents appears to be desired. Research could focus on current highly successful programs to see how they could be implemented in other schools. Lastly, research should be conducted on legal and illegal Hispanic immigrants to determine if immigration status affects the degree and kind of parental involvement. In other words, is parental involvement affected more by immigration status or do the differences between the Hispanic and the majority cultures and the language barrier combine to discourage participation?

\section{Conclusion}

Many reasons exist for school leaders to find and implement solutions to increase the academic achievement of Hispanic immigrant students in the public schools. Beyond the pressures of school accountability as measured by tests, the most important reason is the Hispanic students themselves. Failure to solve the problem of Hispanic student low achievement and subsequent dropping out of school by many will result in a disappointing destiny. Much potential will be unrealized and this group of immigrants will end up as a large underclass of citizens. The time is right and the cause is worthy for American educational leaders to address the problem now.

\section{References}

Aspiazu, G.G., Bauer, S.C., \& Spillett, M.D. (1998). Improving the academic performance of Hispanic youth: A community education model. Bilingual Research Journal, 22(2), 1-20.

Bauch, P.A. (1992). Toward an Ecological Perspective on School Choice. Paper presented at the Annual Meeting of the American Educational Research Association, San Francisco, April 20. ED346595.

Brown, G.H., Rosen, N.L., Hill, S.T., \& Olivas, M.A. (1980). The condition of education for Hispanic Americans. NCES-80-303. Washington, D.C.: U.S. Government Printing Office.

Carger, C.L. (1997). Attending to new voices. Educational Leadership, 54,(7), 39-43.

Chavkin, N.F. \& Gonzalez, D.L. (1995). Forging partnerships between Mexican American parents and the schools. West Virginia: ERIC Clearinghouse on Rural
Education and Small Schools. (ERIC Document Reproduction Service No. ED388489).

Costa, M. (1991). Hispanic Parental Involvement. M.S. Practicum, Nova University. ED 339462.

Espinosa, L.M. (1995). Hispanic parent involvement in early childhood programs. ERIC Clearinghouse on Elementary and Early Childhood Education. (ERIC Document Reproduction Service No. ED382412).

Ferrer, L. (2007). Why is Hispanic Parental Involvement a Serious Issue? National Education Association. Retrieved January 29, 2008 from http://www.abcarticledirectory.com/Article/Why-IsHispanic-Parental-Involvement-A-Serious-Issue-/117748

Floyd, L. (1998, March). Joining hands: A parental involvement program. Urban Education, 33(1), 123-135.

Fuentes, F., Cantu, V.D., \& Stechuk, R. (1996). Migrant head start: what does it mean to involve parents in program services? Children Today, 24(1), 16-18.

Gibson, M.A. (2002). The new Latino diaspora and educational policy: Education in the new Latino diaspora: Policy and the politics of identity. Westport, CT: Ablex Publishing.

Hampton, F.M., Mumford, D.A., \& Bond, L. (1998, September). Parent involvement in inner-city schools: The project FAST extended family approach to success. Urban Education, 33(3), 410-427.

Haycock, K., \& Duany, L. (1991, January). Developing the potential in Latino students. Principal, 70(3), 25-27.

Henderson, A., \& Mapp, K. (2002). A new wave of evidence: The impact of school, family, and community connections on student achievement, Austin, TX: Southwest Educational Development Laboratory.

Hyslop, N. (2000). Hispanic parental involvement in home literacy. ERIC Clearinghouse on Reading, English, and Communication. (ERIC Document Reproduction Service No. 446340).

Inger, M. (1992). Increasing the school involvement of Hispanic parents. ERIC Clearinghouse on Urban Education. (ERIC/CUE Digest No. 80, ED 350380).

Lopez, G.R. (2001, Fall). The value of hard work: Lessons on parent involvement from an (im)migrant household. Harvard Educational Review, 71(3), 416-437.

National Center of Educational Statistics (2002). Statistical Standards. Retrieved January 29, 2008 from http://nces.ed.gov/statprog/2002/glossary.asp\#hispanic

National Council of La Raza (1992). State of Hispanic American 1991: An overview. Washington, DC: National Council of La Raza.

Nicolau, S., and C.L. Ramos. (1990). Together is better: building strong relationships between schools and Hispanic parents. New York: Hispanic Policy Development Project. (ERIC Document Reproduction Service No. ED 325543).

Patton, M. Q. (2002). Qualitative research and evaluation methods. ( $3^{\text {rd }}$ ed.) Thousand Oaks, CA: Sage

Publications. 
Schmid, C. L. (2001). Educational achievement, languageminority students, and the new second generation. Sociology of Education, Supplement: Currents of Thought: Sociology of Education at the Dawn of the 21 ${ }^{\text {st }}$ Century, 71-87. Retrieved Sept.2, 2004 from http://www.ncrel.org/gap/library/text/ differentfactors.html

Scribner, J.D., Young, M.D., \& Pedroza, A. (1999). Building collaborative relationships with parents. In P. Reyes, J.D. Scribner, \& A.P. Scribner (Eds.), Lessons from high-performing Hispanic schools: Creating learning communities. New York: Teachers College Press.

Shannon, S.M. (1996, Nov.). Minority parental involvement: A Mexican mother's experience and a teacher's interpretation. Education \& Urban Society, 29(1), 71-84.

Sosa, A.S. (1997). Involving Hispanic parents in educational activities through collaborative relationships. Bilingual Research Journal, 21(2), 1-8.
Trumbull, E., Rothstein-Fisch, C., Greenfield, P.M., \& Quiroz, B. (2001). Bridging cultures between home and schools: A guide for teachers. Mahway, NJ: Lawrence Erlbaum Associates.

U.S. Census Bureau. (2000). The Hispanic Population: Census 2000 Brief. U.S. Census Bureau. Census 2000 Brief No. C2KBR/01-3. Washington, DC. Retrieved November 16, 2005 from http://www.census.gov/prod/2001pubs/c2kbro1-3.pdf United States Department of Agriculture Economic Research Service. (2002). New Patterns Of Hispanic Settlement. RDRR-99.U.S. Department of Education, Valverde, S.A. (1987). A comparative study of Hispanic high school dropouts and graduates: Why some leave school early and some finish? Education and Urban Society, 193(3), 320-329. 